\title{
Canton de Vouvray
}

$n^{\circ} 068494$

\section{Pascal Alilaire et Agnès Couderc}

\section{(2) OpenEdition \\ 1 Journals}

Édition électronique

URL : http://journals.openedition.org/adlfi/13783

ISSN : 2114-0502

Éditeur

Ministère de la culture

Référence électronique

Pascal Alilaire et Agnès Couderc, "Canton de Vouvray », ADLFI. Archéologie de la France - Informations [En ligne], Centre, mis en ligne le 28 octobre 2014, consulté le 03 mai 2019. URL : http:// journals.openedition.org/adlfi/13783

Ce document a été généré automatiquement le 3 mai 2019.

(c) Ministère de la Culture et de la Communication, CNRS 


\title{
Canton de Vouvray
}

$n^{\circ} 068494$

\author{
Pascal Alilaire et Agnès Couderc
}

Lien Atlas (MCC) : http://atlas.patrimoines.culture.fr/atlas/trunk/index.php?

ap_theme=DOM_2.01.02\&ap_bbox $=0.770 ; 47.393 ; 0.839 ; 47.469$

1 Le programme de la Carte Archéologique a été poursuivi en 1997 sur le canton de Vouvray, où l'inventaire général des sites a été réalisé sur les 10 communes de Chançay, Chanceaux-sur-Choisille, Monnaie, Neuillé-le-Lierre, Noizay, Parçay-Meslay, Reugny, Rochecorbon, Vernou-sur-Brenne et Vouvray. Il s'ajoute aux opérations antérieures entreprises dès août 1992 au Grand-Pressigny et désormais achevées sur 7 cantons. Les prospections au sol n'ont pas été effectuées sur la commune de Notre-Dame-d'Oé, objet d'un remembrement récent et dont le cadastre est en cours de mise à jour. Les résultats, avec l'exploration de nouveaux secteurs où rien n'était encore inventorié, sont très positifs. L'enquête orale, l'inventaire des collections privées et les investigations de terrain ont permis en effet de recenser de nombreux sites inédits et de toutes périodes.

257 sites et indices paléolithiques ont été répertoriés. La plus forte concentration de ces vestiges se trouve sur la commune de Vernou, dans les vallées de Cousse et de Vaugondy, où de vastes zones d'occupation, habitats et ateliers de taille du silex, ont été cartographiés. L'abondance des industries s'explique par la présence de silex turoniens englobés dans les argiles et les colluvions de pente. Ces matériaux se trouvent en grande quantité au pied des versants et dans les fonds de vallées, où les accumulations peuvent atteindre plusieurs mètres d'épaisseur (jusqu'à $10 \mathrm{~m}$ dans la vallée de Vaugondy). Les matières sont diversifiées : silex noir du Turonien ancien, silex grisâtre parfois zoné du Turonien moyen et silex brun (avec de nombreuses variantes) du Turonien supérieur. Ce dernier, de très bonne qualité, est le plus utilisé. Un des secteurs les plus riches se situe aux alentours de la ferme des Landes où les vestiges sont disséminés sur plusieurs dizaines d'hectares. Il a livré des centaines de bifaces représentatifs, pour la majorité, du Moustérien typique et du Moustérien de tradition acheuléenne. 
3 Les sites néolithiques (103 sites et indices) sont principalement représentés par des habitats et quelques ateliers de taille du silex. L'occupation est encore très importante sur la commune de Vernou, favorisée par des emplacements topographiques très remarquables et la présence de matière première. Des ateliers de taille jalonnent les versants et les rebords de plateaux dans les vallées de Cousse et de Vaugondy où les gisements de silex turonien fournissaient un matériau de choix. Les déchets de débitage jonchent de nombreux emplacements, notamment aux alentours des Landes et près de Villeméreau, ainsi que sur la frange du plateau dominant la Loire, la confluence de la Brenne à Vernou. Une zone exceptionnelle apparaît dans les Varennes sur la rive gauche de la Cisse. L'habitat est développé sur une vaste montille formée en bordure d'un ancien lit de crue de la Cisse. Plusieurs concentrations y ont été localisées aux lieux-dits les Terres de la Noue du Pot, et les Terres de la Noue Amère. Elles recèlent une riche industrie (l'occupation a perduré aux périodes protohistoriques, gallo-romaines et médiévales).

\section{INDEX}

Index chronologique : Paléolithique

Index géographique : Centre, Indre-et-Loire (37), Vouvray

operation Prospection inventaire (PI)

Mots-clés : atelier, habitat, silex 